\title{
Simulating groundwater contaminant migration at Villa Farm lagoons
}

\author{
R. Mackay ${ }^{1}$, M. S. Riley ${ }^{1}$ \& G. M. Williams ${ }^{2}$ \\ ${ }^{1}$ School of Earth Sciences, University of Birmingham, Edgbaston, Birmingham B15 2TT, UK \\ ${ }^{2}$ Fluid Processes Research Group, British Geological Survey, Keyworth, NG12 5GG, UK
}

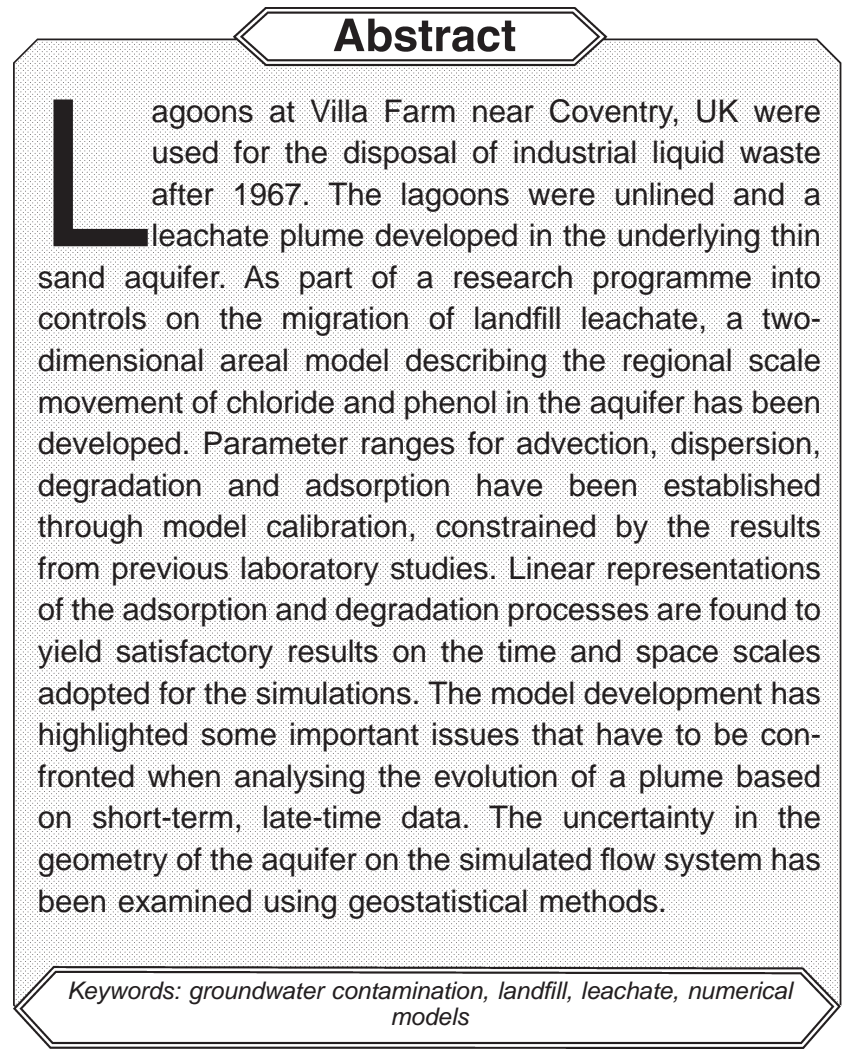

\section{Introduction}

Leachate derived from landfill sites can degrade the quality of the underlying groundwater resource. The extent to which the groundwater quality is affected depends on the rate of release of leachate into the subsurface and on the spread of the contamination in the aquifer. Advective and dispersive processes act to distribute the leachate through the aquifer, while chemical and biological processes can control the migration of some, or all, of the leachate components.

As part of a major study of the migration of leachate in groundwaters, a model has been developed to examine the regional controls on the growth of the contaminant plume beneath the lagoons at Villa Farm, an industrial liquid-waste disposal site. The main focus of the modelling has been to simulate the macroscopic behaviour of two species in the plume, chloride and phenol, and to determine, through a calibration exercise, the magnitude of the model parameters describing the processes of advection, dispersion, adsorption and degradation.
Modelling of the leachate plume's development has been undertaken in four distinct phases:

(1) Development of a conceptual model of the groundwater flow regime;

(2) Implementation and calibration of a numerical model to simulate the spatial patterns of groundwater flow in the vicinity of the lagoons;

(3) Simulation of the hydrodynamic processes of advection and dispersion based upon calibration using chloride data;

(4) Simulation of the processes of adsorption and degradation affecting phenol migration.

The aim of this paper is to present the modelling results and the important modelling issues that can arise when attempting to predict the fate of contaminants quantitatively. Of particular interest is the derivation of parameter values from point data collected over a short period at late-times, when the contaminant plume is well developed.

\section{The site}

\section{Background}

The lagoons at Villa Farm have an area of less than $2500 \mathrm{~m}^{2}$ and originally comprised a group of shallow excavations produced during sand extraction. Between 1945 and 1967, these excavations were used for the disposal of minor quantities of solid domestic refuse and rubble. Subsequently, the site was adopted for the disposal of liquid industrial wastes. The lagoons were used as a temporary holding facility for the separation of oils from the aqueous phase of the liquid waste and for the neutralization of the wastes before removal for recycling or safe disposal elsewhere. Sludge was removed once or twice a year from the lagoons, stockpiled and then transported to a local landfill. Records of the type and volume of the waste disposed at the site are not available prior to the introduction of the Deposit of Poisonous Wastes Act in 1972. General categories of waste deposited during the period 1978 to 1980 and their total volumes are shown in Table 1. In 1982, all waste disposal ceased. The nature of the industries using the site suggests that the character of the wastes changed little over the period of the site's usage.

The lagoons are at least $4 \mathrm{~m}$ deep and the walls and base of the lagoons are unlined suggesting potentially 
Table 1. Deposit of wastes at Villa Farm Lagoons (tonnes) 1978/80

\begin{tabular}{lrc}
\hline Waste category & $78 / 79$ & $79 / 80$ \\
\hline (1) Alkali metal oxide and hydroxide sludge alkaline cleaners & 3441 & 321 \\
(2) Toxic metal sludges containing Pb, Zn, Ba, Ni, Cu, Cr; neutralized chromic acid & 12202 & 2736 \\
(3) Non-toxic metal compounds (Fe) & 1820 & - \\
(4) Inorganic compounds, chromates, nitrates & 734 \\
(5) Miscellaneous inorganic compounds & 73 & -168 \\
(6) Organic wastes, halogenated hydrocarbons, chelating agents & 24 & 1.5 \\
(7) Oils: mineral & 33 & - \\
$\quad$ vegetable and other & 10913 & 168 \\
oil/water mixtures & 7632 & 1714 \\
(8) Industrial effluent treatment sludge & 3903 & 1577 \\
(9) Printing ink wastes, paint waste & - & 108 \\
(10) Food processing waste (starch) &
\end{tabular}

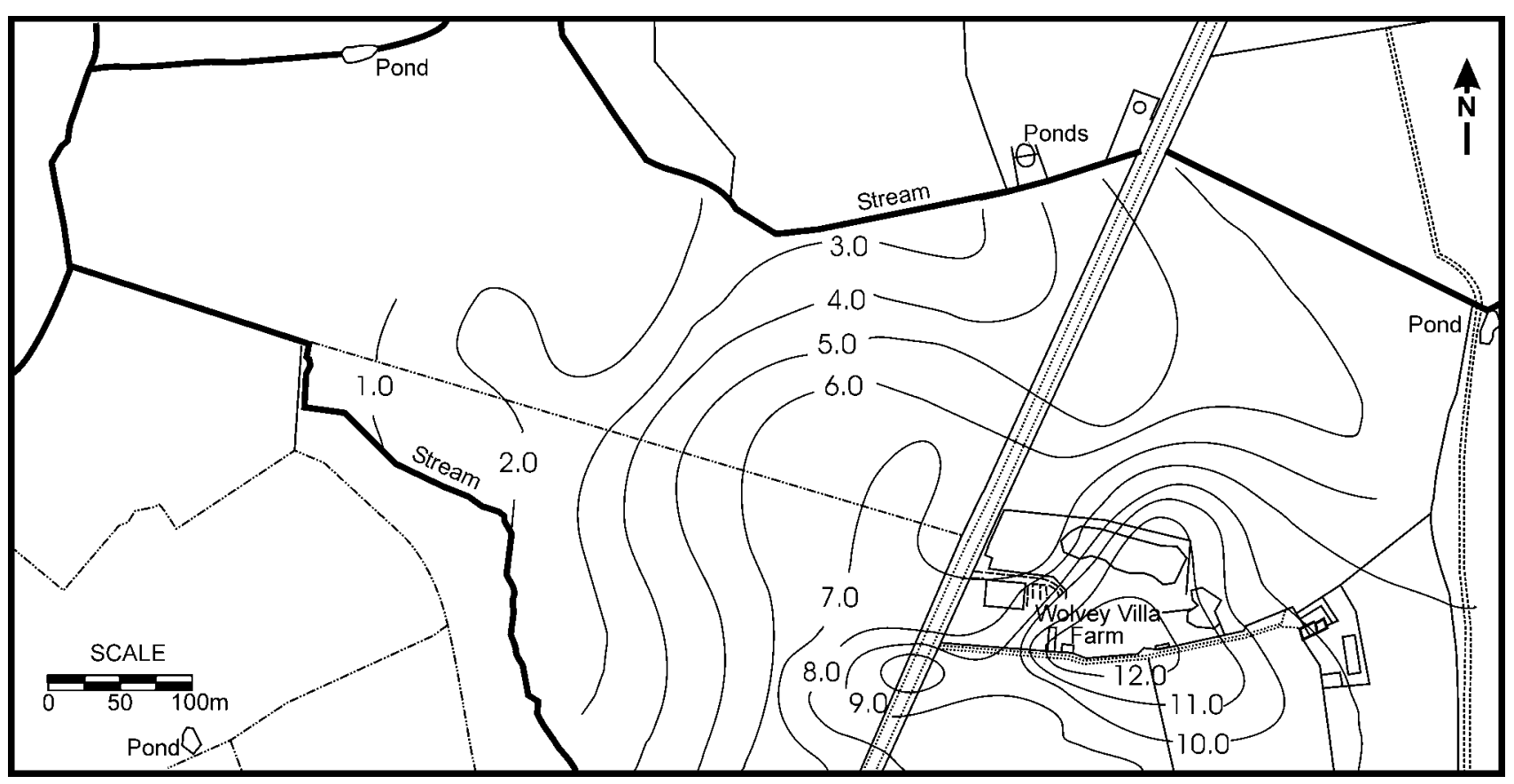

Fig. 1. Site plan of aquifer thickness (m).

high infiltration rates. However, the build up of sludges in the lagoons seems to have restricted the rate of leachate migration to the aquifer. Over the four years following the closure of the site, the fluid level remained approximately $3 \mathrm{~m}$ above the regional groundwater level. The periodic removal of the sludges is believed to have disturbed the sealing layer on the walls of the lagoon leading to intermittent rapid injection of leachate into the groundwater system. This mechanism provides one explanation for the presence of leachate in the aquifer east of the lagoons, which suggests migration against the general direction of groundwater flow.

The lagoons penetrate the Wolston Sands formation. This formation is sandwiched between underlying and overlying clay units and is the primary aquifer unit in the upper sequence of sediments. The formation is composed of lacustrine sands and ranges in thickness between 1 and $13 \mathrm{~m}$ across the site. The formation is thickest in the vicinity of the lagoons where a scour hollow, cut into the lake clays, has been infilled by the sands. The lower clay is vertically extensive and provides an effective low permeability barrier to downward leakage of groundwater. The upper clay layer is less substantial (1-3 m thick) and provides a semi-permeable barrier to vertical leakage from surface water infiltration. A plan of the site showing the regional variation in the thickness of the aquifer is presented in Fig. 1.

\section{The database}

Hydrogeological and hydrogeochemical data were collected at the site from 1975 (Williams et al. 1984). The major emphasis of the data collection programme was 
Table 2. Power law variogram model parameter estimates

\begin{tabular}{lcccrc}
\hline Surface & \multicolumn{3}{c}{ Variogram parameters } & \multicolumn{2}{c}{ Standardized errors } \\
& $a$ & $b$ & $c$ & Mean & 1.045 \\
\hline Top of aquifer & 0 & 0.15 & 0.5 & 0.004 & 1.145 \\
Base of aquifer & 0 & 0.18 & 0.8 & -0.009 & \\
\hline
\end{tabular}

on the groundwater chemistry of the plume in order to provide a three-dimensional picture of the distributions of the main components of the leachate. Geological logs prepared from 84 boreholes provided data describing the geometry of the aquifer beneath the site. The boreholes were either cored or drilled by percussion methods and were sited, in the main, to penetrate the contamination plume to the west of the lagoons. Rest water level measurements were taken, and hydrographical records were maintained at sixteen boreholes for a 14-month period during 1982 and 1983. Hydraulic testing yielded data at a few sites using slug and short duration constant rate tests on packered borehole sections. Meteorological data were obtained from the Meteorological Office.

\section{The basic conceptual model}

From the database, a conceptual model of the main features of the groundwater flow system was established describing the aquifer geometry, confining conditions, the conditions in the lagoons, the form of the lateral flow boundary conditions and recharge and discharge distributions. Its function was to provide the basis for the subsequent flow and transport simulations and consequently did not include hydraulic or transport parameter values.

\section{Dimensionality}

The chemical data exhibit strong concentration variations with depth and, in several boreholes, higher concentrations are observed near the aquifer base, which suggested a possible dependency of the plume's extent on vertical migration processes. However, the additional complexity of modelling the vertical fluxes could not be justified given the limited data describing the lagoons and the aquifer's hydraulic and piezometric distributions in the vertical. A two-dimensional, areal representation of the aquifer was adopted for the modelling in which vertically averaged properties are assumed and only lateral flow and transport are considered. The small thickness of the sand formation relative to its lateral extent further justified this approximation.

\section{Aquifer geometry}

The geostatistical method of Universal Kriging, which allows spatial trends to be taken into account was used to define the aquifer geometry. For a description of Kriging and its application in hydrogeology see Kitanidis (1997), or Marsily (1986). In addition to providing a 'best linear, unbiased' estimate of the top and bottom surfaces of the aquifer, Universal Kriging also provides a measure of the variance of the estimation error at every point. The correlation structures for both surfaces required for application of the Kriging equations were characterized by isotropic, power law semi-variograms (including nugget effect), $\gamma(h)$, of the form

$$
\gamma(h)=a+b h^{c}
$$

where $h$ is the horizontal separation between points on the interpolated surfaces [L]

$a$ is the magnitude of the nugget effect [L]

$b$ and $c$ are dimensionless constants [1]

The semi-variogram model parameter values for the base and top of the aquifer are given in Table 2. The validity of the variogram models was tested by deleting each data point in turn; Kriging using the remaining data points to give an estimated value at that point; and, comparing the estimates with the observed values.

\section{Confining conditions}

The aquifer is partially confined over much of the area by the overlying clay. To the east of the domain, the base of the clay lies above the water table, but the clay intercepts the capillary fringe, reducing the specific yield. Thus partially confining conditions were assumed over the entire aquifer. A short modelling study was conducted, which demonstrated that the transport of a conservative chemical species through the aquifer is insensitive to this assumption.

\section{Flow boundary conditions}

The model flow domain is shown in Figure 1. The streams on the western and northern boundaries are considered to act as the principal sinks to groundwater flow and were characterized as prescribed head boundaries. Along the streams the connection to the aquifer is unlikely to be total due to the effects of partial penetration into the sands, the existence of bed debris and the reduction in thickness of the sand in the area with an 
attendant increase in clay content. The prescribed heads were set to be $0.3 \mathrm{~m}$ above the observed stream water levels to provide an approximate representation of the equivalent groundwater head adjacent to the stream. This correction was necessary as the chosen numerical model assumes essentially horizontal flow to a prescribed head boundary.

The kriged aquifer base and top elevations indirectly provide a best estimate thickness of between 1 and $2 \mathrm{~m}$ along the northern boundary. However, the uncertainty estimated by the kriging standard deviations for the aquifer top and base elevations indicate that the sands may pinch out completely, implying the possibility of a no flow boundary condition. While this possibility was acknowledged for the uncertainty calculations, the best estimates were taken to represent the most likely aquifer conditions along this boundary.

Contoured water levels indicate the dominant flow direction to be from east to west. To the east, the aquifer base elevation rises sharply and an increase in hydraulic gradient is observed. It would appear that in this region the base of the aquifer is acting as a subsurface weir maintaining the up-gradient groundwater levels during the low recharge months and releasing, with only a minor change in water level, a substantial quantity of water when recharge is at a high level. A prescribed head boundary condition was adopted to simulate outflow from the model area over the crest of the 'weir'. From the available hydrographical data, it also seems likely that the east-west flow direction does not vary significantly through the year, and so a no flow boundary condition has been imposed on the southern boundary to simulate an east-west streamline.

\section{Recharge}

Analysis of the meteorological record and the assumed vertical hydraulic conductivity of the overlying clay indicated that a uniform recharge from precipitation of about $50 \mathrm{~mm} / \mathrm{a}$ was appropriate. In addition, the lagoons recharge the aquifer directly with leachate. Observations of the steep hydraulic gradients in the vicinity of the lagoons, coupled with apparently insignificant change in the lagoon fluid levels between disposal operations, strongly imply that the effective infiltration rate must be lower than volumes estimated from waste disposal records. A pulsed leachate input was adopted based on seepage through the walls of the lagoons for a short period following each sludge extraction (twice-yearly). The rate of seepage is calculated directly from the observed head differences and the exposed contact area of permeable sand. The effect of undiluted leachate on the effective hydraulic conductivity of the sand was not considered in this calculation.

\section{Regional Groundwater Flow}

\section{The numerical model}

The model of groundwater flow adopted in this study assumes essentially horizontal flow, a constant density fluid and constant aquifer properties. The resulting mass balance equation was solved using the computer code FEPOLL, which employs a Galerkin finite element scheme (Shapiro 1984).

\section{Flow model calibration}

Vertically averaged hydraulic conductivities were defined at the node points of the model mesh. These parameter values were adjusted manually until simulated heads were within $0.1 \mathrm{~m}$ of the observed heads and the simulated hydraulic gradients were within $5 \%$ of the observed gradients. Recharge rates to the aquifer and the applied boundary conditions were held constant during calibration. Isotropy of the hydraulic conductivity tensor was assumed. The effective hydraulic conductivity was assumed to be a smoothly varying function within the modelled region. A first estimate of the distribution of the hydraulic conductivity was made based on evidence from the hydraulic testing programme. Analysis of the data suggested a correlation between aquifer thickness and conductivity: lower conductivity values appeared to be associated with regions of reduced aquifer thickness. Owing to the nature of the imposed fixed head boundary conditions, the initial calibration runs showed the hydraulic gradients in the central region to be generally insensitive to large changes in hydraulic properties. Manual calibration was preferred to automatic calibration procedures in this instance because of this insensitivity. The volumes of water released to the streams from the groundwater were too small to be directly measurable. The calibrated hydraulic conductivity distribution is shown in Fig. 2. The flow model derived from the main calibration exercise was used to support the transport simulations. The plume data were not used in this exercise to constrain the calibration.

\section{Conceptual model uncertainty}

An analysis was undertaken of the sensitivity of the simulated flow directions to uncertainties in the conceptual model. The basic conceptual model defined above was assumed to be known with certainty, but parameter values and the structure of the hydraulic conductivity distribution were considered to be uncertain. Alternative, full conceptual models were built by assigning ranges of values to the prescribed head boundaries and recharge rates from the lagoons, and by incorporating a variety of alternative mesh-scale heterogeneity patterns 


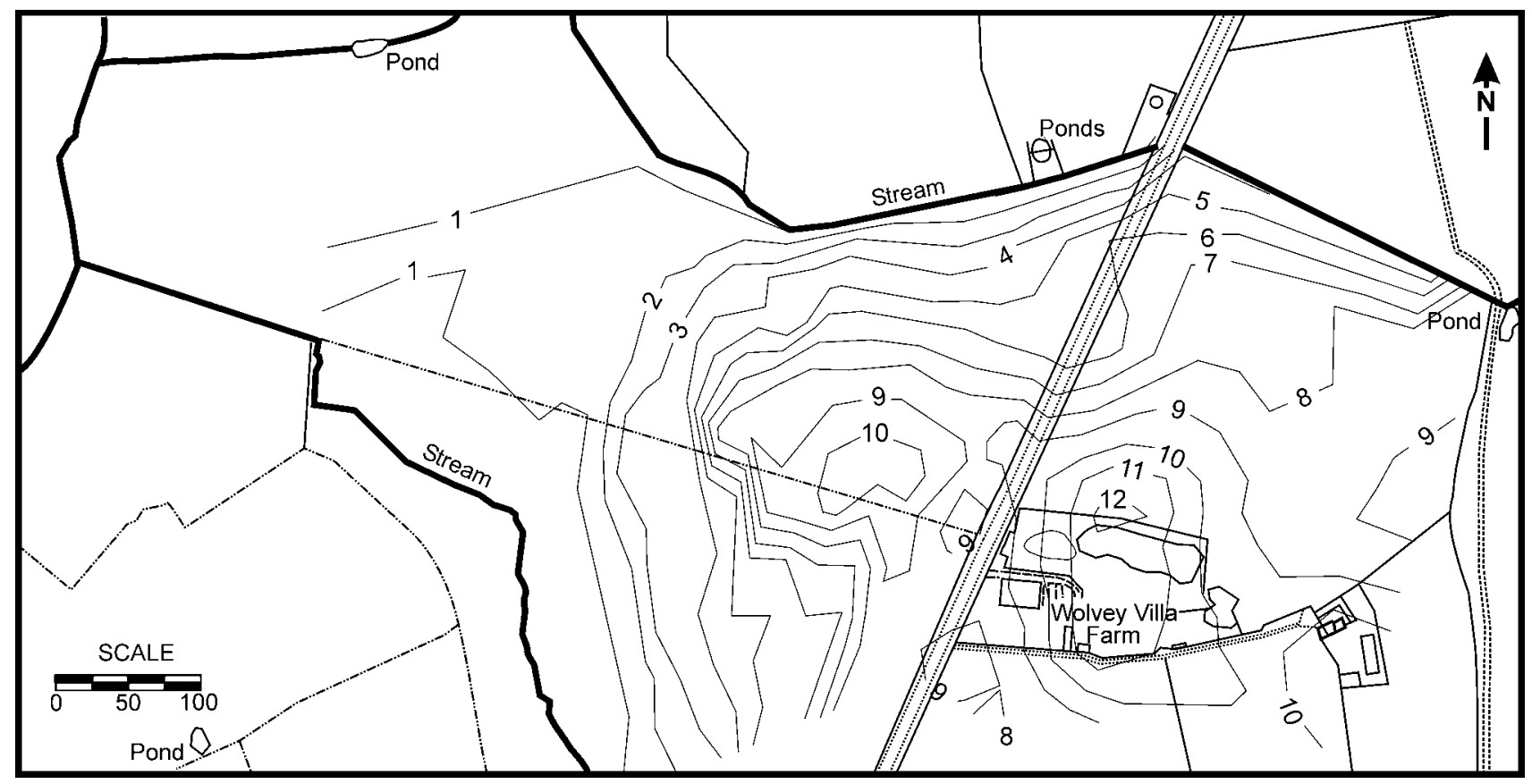

Fig. 2. Steady state calibrated hydraulic conductivity distribution $\left(\mathrm{md}^{-1}\right)$.

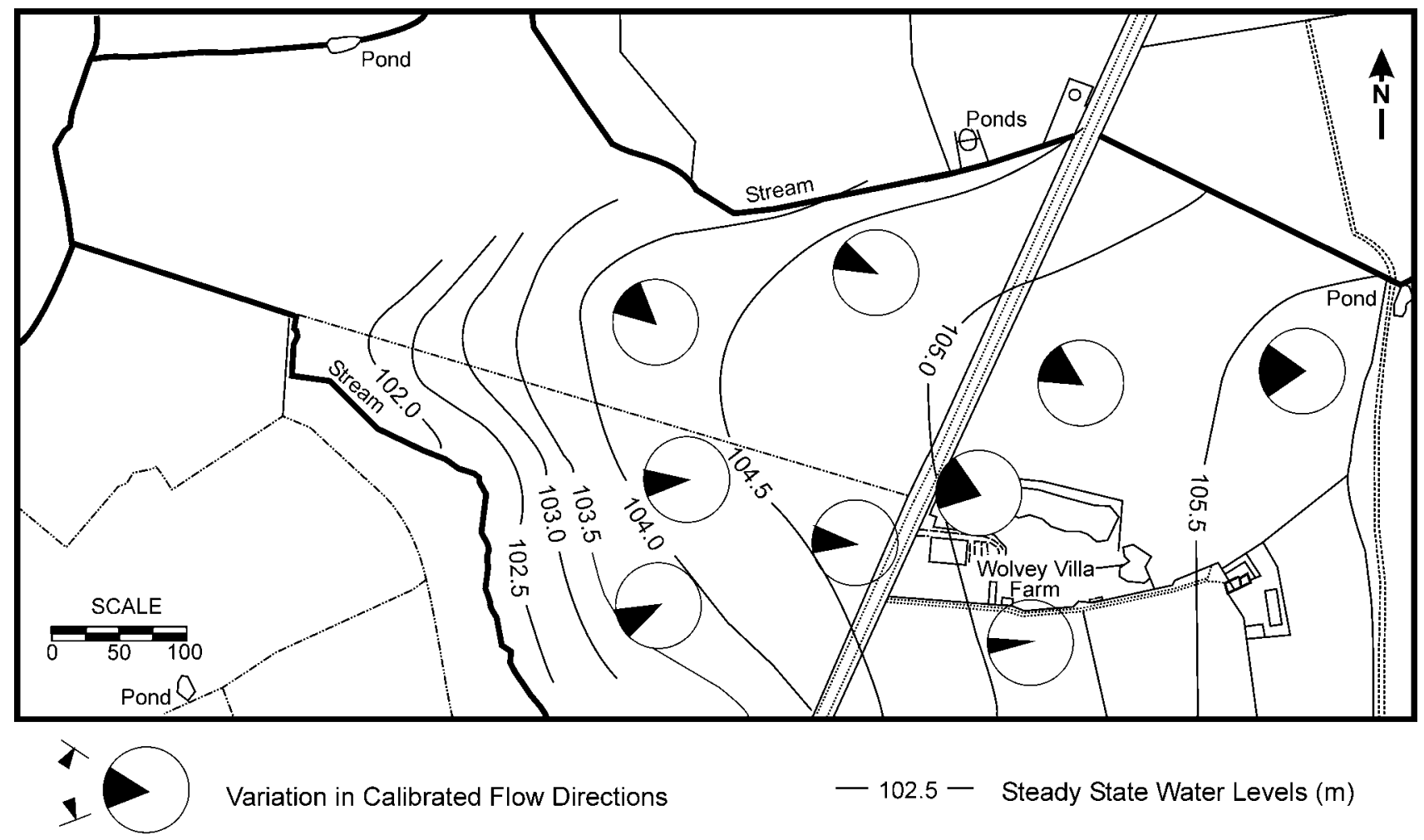

Fig. 3. Uncertainty in flow directions at selected points.

for the distribution of hydraulic conductivity. Hydraulic conductivities along the northern boundary were allowed to approach zero in some models to represent pinching out of the aquifer in this region. For each model, a manual recalibration exercise was conducted using the mesh hydraulic conductivity values as calibration parameters. Conceptual models that could not be calibrated to reproduce the observed head distribution to within the tolerances specified above were rejected.

Figure 3 shows the variation in simulated flow directions, at selected points in the domain, obtained from 
the alternative calibrated models. No account was taken of the chemical data in the formulation of the alternative conceptual models. A more complete description of this component of the study is given in Mackay et al. 1986.

The variations between conceptual model results are very marked, as expected. It can be inferred from these results that, even in a study with an extensive hydrological data set, conceptual model error may constitute a major component of the overall uncertainty. In the majority of studies of subsurface contaminant migration in which data are more limited, the problem is likely to be even more acute. Stochastic methods are now being used to quantify more rigorously the uncertainty in transport model predictions (Delhomme 1979; Mackay et al. 1988). However, applications of these approaches have concentrated on defining only the uncertainty in the predictions due to the variability of the hydraulic properties. This study indicates that such approaches may not identify the true extent of the uncertainty in the model results.

\section{Plume development}

\section{Background}

Two factors facilitate the simulation of the pollution plume at Villa Farm. First, the lagoons discharge directly into the saturated zone. Hence, evaluation of the effects of attenuation and degradation processes that normally occur in the unsaturated zones beneath landfills is avoided. Second, the extent of the plume can be characterized by the presence of chloride. Low chloride concentrations $(20 \mathrm{mg} / \mathrm{l})$ are found in the natural groundwaters. This compares with the chloride levels in the leachate in excess of $3000 \mathrm{mg} / \mathrm{l}$. As chloride is generally regarded as a conservative tracer, it provides a useful indicator of the physical transport processes occurring in the groundwater regime.

The main assumptions made in the transport modelling are:

(1) mean groundwater flow conditions are dominant in controlling the advective migration of contaminants;

(2) the effective porosity of the aquifer is uniform with a value of 0.2 ;

(3) the aquifer is homogeneous and isotropic with respect to its dispersion properties;

(4) the leachate release rate from the lagoons is $1000 \mathrm{~m}^{3} / \mathrm{a}$;

(5) no interference occurs between the chemical species of interest in the groundwater;

(6) concentrations averaged over depth derived from the available field data provide an adequate description of contaminant distributions for the purposes of calibrating the parameters of degradation and adsorption.

\section{The numerical model}

The numerical model chosen for the development of the pollution plume was SUTRA (Voss 1984). This model uses a mixed Galerkin finite element/integrated finite difference scheme for the numerical solution of both the fluid flow and solute transport equations. The code assumes confined aquifer conditions for twodimensional areal problems. Whilst the Wolston sands are partially unconfined east of the lagoons, the assumption of fully confined conditions within SUTRA was shown to be unimportant for the transport simulations performed in this study. The model allows for transport of single solutes that may be subject to adsorption and decay or production. The form of the total solute species mass balance used in SUTRA for saturated flow is:

$$
\begin{gathered}
\frac{\partial}{\partial t}(n \rho C)+\frac{\partial}{\partial t}\left[(1-n) \rho_{s} C_{s}\right]=-\frac{\partial}{\partial x_{i}}\left(n \rho V_{i} C\right) \\
+\frac{\partial}{\partial x_{i}}\left(n \rho D_{i j} \frac{\partial C}{\partial x_{j}}\right)+n \rho \Gamma_{w}+(1-n) \rho_{s} \Gamma_{s}+C^{\prime} W
\end{gathered}
$$

where $n=$ porosity [1]

$\rho=$ fluid density $\left[\mathrm{ML}^{-3}\right]$

$\rho_{s}=$ solid grain density $\left[\mathrm{ML}^{-3}\right]$

$C=$ solute mass per unit mass of water [1]

$C_{s}=$ adsorbed solute mass per unit mass of rock [1]

$V_{i}=i$ th component of the velocity vector $\left[\mathrm{LT}^{-1}\right]$

$D_{i j}=i j$ th component of the dispersion tensor $\left[\mathrm{L}^{2} \mathrm{~T}^{-1}\right]$

$\Gamma_{w}=$ solute mass production/decay rate $\left[\mathrm{T}^{-1}\right]$

$\Gamma_{s}=$ adsorbed mass production/decay rate $\left[\mathrm{T}^{-1}\right]$

$W=$ source/sink discharge per unit volume of medium $\left[\mathrm{T}^{-1}\right]$

$C^{\prime}=$ solute concentration of source sink discharge $\left[\mathrm{ML}^{-3}\right]$

The accuracy of the numerical solution of the transport equation depends on the discretization of the domain. For small dispersivities a very fine mesh is required, leading to the need for large numbers of elements. To minimize the computational effort, a mesh of 3000 elements was constructed covering only the area to the west of the lagoons containing the plume (Fig. 4). To obtain the velocity distribution at the fine mesh scale, the flow problem was also solved using this mesh. The physical data from the calibrated groundwater flow model were transferred to the refined mesh using an automatic interpolator based on inverse distance weighting and prescribed heads were assigned to the full boundary of the transport model using a similar scheme. This transformation was shown to reproduce the flow field in the transport model accurately. Solute flux boundary conditions were used on the boundaries of the transport model domain. 


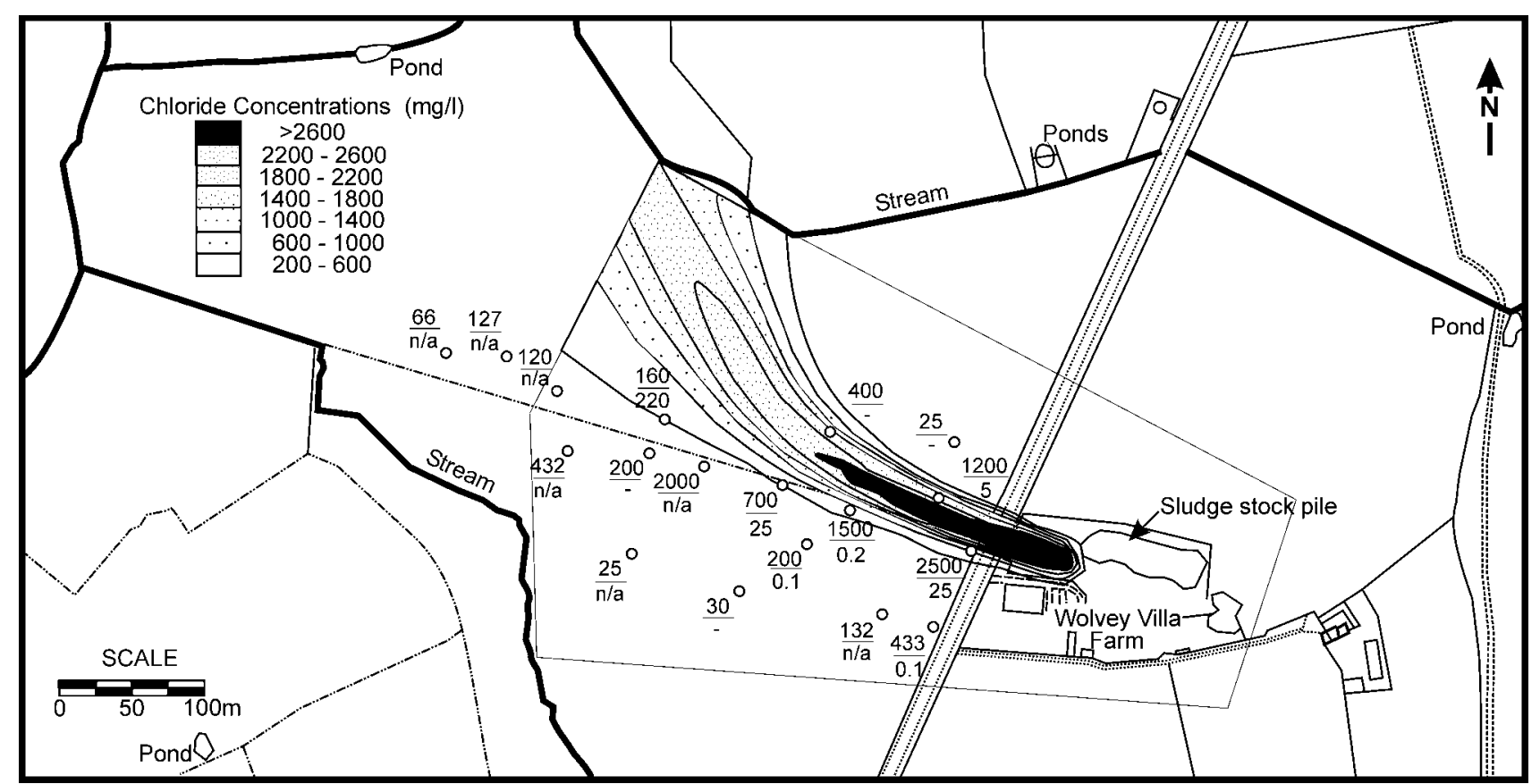

Fig. 4. Modelled chloride plume-1982; Dispersivity Pair- $(2.5 \mathrm{~m}, 0.25 \mathrm{~m})$; Observed concentrations are given in $\mathrm{mg} / \mathrm{l}$ as chloride/phenol. Phenol concentrations marked '-' were below detection limits. Where phenol was not sampled, the concentration is marked as ' $\mathrm{n} / \mathrm{a}$ '.

Table 3. Dispersivity pairs used for simulation $(m)$

\begin{tabular}{lrl}
\hline & $\alpha_{L}$ & $\alpha_{T}$ \\
\hline 1 & 2.5 & 0.25 \\
2 & 5.0 & 0.25 \\
3 & 5.0 & 0.50 \\
4 & 7.5 & 0.50 \\
5 & 10.0 & 0.50 \\
\hline
\end{tabular}

\section{Plume simulation-conservative transport}

Fick's Law is assumed to describe the dispersive flux in the groundwater and molecular diffusion assumed to be negligible. Modelling of the chloride plume was undertaken to establish the magnitude of both transverse and longitudinal dispersivity, which were assumed to be constants for the aquifer. Five dispersivity pairs were introduced into the model to examine their effect on the plume shape (Table 3). Assuming no pollution prior to 1967, 15-year simulations were carried out to reproduce the plume's development through to 1982 when most chemical data were collected. An example of the simulated plume geometry for 1982 is shown in Figure 4. Analysis of the development of the plume showed that at early times the plume shape is most sensitive to the longitudinal dispersivity. As the plume enlarges, the sensitivity of the concentration profiles to longitudinal dispersivity decreases rapidly, tending to zero as the plume approaches steady state. Since the plume at Villa Farm was already well developed by the time the field programme was instigated and the main chemical data collected, calibration of this parameter could not meaningfully be carried out.

By contrast, changes to the transverse dispersivity have a significantly greater impact on the plume shape. From the results of the simulations, a value of transverse dispersivity between 0.2 and $0.4 \mathrm{~m}$ is appropriate for the aquifer. Since results from field experiments indicate that longitudinal dispersivity generally exceeds the transverse dispersivity by at least a factor of ten but usually not more than twenty (Anderson 1979; Klotz et al. 1980; Gelhar et al. 1992) it is reasonable to infer that the longitudinal dispersivity lies in the range 2 to $8 \mathrm{~m}$.

Although direct comparison of the field measurements with the simulation results is not easy given the uncertainties in the source term, the simulated concentration distributions exhibit the main features of the observation data but are higher than those observed. This would suggest that the assumption of an injection rate of $1000 \mathrm{~m}^{3} / \mathrm{a}$ could be too high and that a figure as low as $500 \mathrm{~m}^{3} / \mathrm{a}$ may be more appropriate. Without better evidence as to the cause of this discrepancy, it was decided to maintain the original injection rate for all simulations since the characteristic plume shape can be shown to be largely independent of this figure. The simulations tend to underestimate the observed spread of the pollution adjacent to the lagoons but produce reasonable agreement a short distance downstream. This is partly due to the adoption of steady state flow conditions but may also be due to the decision to confine the leachate production to the lagoons and not to allow a small term in the model to account for seepage from the adjacent sludge stockpile. 
Field data indicate a chloride concentration below the lagoons as high as $4000 \mathrm{mg} / \mathrm{l}$, which is similar to that of the waste. This implies little dilution of leachate by native groundwater. It is assumed that this inhibition of the natural mixing processes is the result of invasion of the aquifer by components of the leachate that reduce the permeability of the sands close to the lagoons. This effect was incorporated in the model by reducing the transmissivity of the aquifer beneath the lagoons. A further reduction was made to account for the reduced thickness of the sands due to the penetration into the aquifer of the lagoons themselves. A total reduction in transmissivity (from the value determined using the kriged aquifer top) of $80 \%$ was required to match the observed chloride concentrations locally at the end of a simulated 15-year period. However, achieving this match resulted in overestimated concentrations downstream. The introduction of a pulsed input of leachate, designed to simulate the effect of periodic dredging of the lagoons to remove low permeability sludge, had the effect of restoring downstream chloride concentrations to observed levels.

The orientation of the tail of the plume deviates from that previously interpreted by examination of the peak concentration distribution in the aquifer (Williams et al. 1984). However, comparison with the available point data shows that either interpretation is acceptable and the model result was adopted as valid. Interestingly, in the early stage of the investigations carried out at the site the plume was expected to have developed preferentially to the north of the lagoons and not to the west as later observed. These two observations provide further evidence of the difficulty of deterministically predicting the migration paths for contaminants in even relatively simple aquifer systems. They also illustrate the interesting but difficult problem of defining an optimal sampling point distribution to characterize the geometry of a pollution plume at the same time as characterizing the chemical patterns within the plume.

\section{Plume simulation-reactive transport}

Most constituents of the leachate are susceptible to adsorption and/or decay within the aquifer. To investigate these processes at Villa Farm, phenol was chosen for detailed simulation. Phenol has been shown from laboratory studies (Phillips 1964; Rees \& King 1980, 1981) to be affected by both processes. In field studies, Williams et al. (1992) report the presence of metabolites of phenol degradation in the aquifer at Villa Farm. The main aim of studying the migration of phenol was to determine the applicability of simple models for adsorption and decay in modelling the macroscopic behaviour of the phenol in the contaminant plume. The question of the applicability of the values of the model derived from laboratory experiments to large scale modelling was also addressed.

\section{Adsorption}

Three equilibrium adsorption isotherms are provided in SUTRA: Linear, Langmuir and Freundlich. The linear isotherm is given by:

$$
C_{s}=K_{D} \rho_{0} C
$$

where $K_{D}=$ linear distribution coefficient $\left[\mathrm{L}^{3} \mathrm{M}^{-1}\right]$ $\rho_{0}=$ fluid reference density $\left[\mathrm{ML}^{-3}\right]$

The data available in the literature indicate that this isotherm is valid for adsorption of phenol in groundwater. Phillips (1964) applied aqueous solutions of phenol to various soil columns to obtain values for the distribution coefficient $K_{D}$ under different conditions. Large differences were found in the values of the coefficient that were obtained. Particular sensitivity was found to the presence of organics and clay in the soils. Values around $2 \times 10^{-7} 1 / \mathrm{mg}$ were measured for sandy and silty loams and $1 \times 10^{-6} 1 / \mathrm{mg}$ for a peaty loam.

Assuming biodegradation to be negligible, several simulations were performed to examine the adsorption for a wide range of values of the distribution coefficient $\left(1 \times 10^{-9}<K_{D}<1 \times 10^{-5} 1 / \mathrm{mg}\right)$. At values greater than the upper limit of this range, the phenol is almost entirely adsorbed while at values less than the lower limit negligible adsorption occurs. Using a value of $1 \times 10^{-6} 1 /$ $\mathrm{mg}$ for the $K_{D}$ for phenol, the simulated ratios of phenol to chloride concentrations in the plume broadly match the phenol to chloride concentration ratios observed in the field (Fig. 4). Given the data presented by Phillips (1964), this would suggest that the Wolston sands are either clay rich or have a significant organic content. Neither feature is observed in the cores of the Wolston Sands. This implies that a lower value for the distribution coefficient is more appropriate and that other mechanisms are also controlling the migration of the phenol.

\section{Biodegradation}

Species production terms, $\Gamma_{w}$ in the water phase and $\Gamma_{s}$ on the surface of the rocks are included in SUTRA as zero or first order reaction rate equations:

$$
\begin{aligned}
& \Gamma_{w}=\gamma_{1}^{w} C+\gamma_{0}^{w} \\
& \Gamma_{s}=\gamma_{1}^{s} C_{s}+\gamma_{0}^{s}
\end{aligned}
$$

where, $\gamma^{w}, \gamma_{0}^{w}, \gamma_{1}^{s}$ and $\gamma_{1}^{s}$, are reaction constants $\left[\mathrm{T}^{-1}\right]$

Rees \& King $(1980,1981)$ present results of experiments on the reaction kinetics of aerobic and anaerobic degradation. Solutions of phenol were applied to columns containing material from the Lower Greensand formation. In Rees \& King's experiments, bacterial activity was found to be concentrated in the upper part of the rock columns, near the source of applied phenol. It is recognized that bacteria may be unable to metabolize organics at low concentrations (Boethling 
and Alexander 1979). On this basis, biological activity at Villa Farm Lagoons would be expected only in the area immediately adjacent to the Lagoons. The strongly reducing chemical environment in this region implies that aerobic bacteria are unlikely to be present and that anaerobic degradation is most likely. Rees and King (1981) observed that anaerobic biodegradation could only be initiated by inoculation with bacteria present in leachate generated from fermenting domestic refuse and at flow rates an order of magnitude lower than those applied in the aerobic case $(0.01-0.03 \mathrm{~m} /$ hour$)$. Flow rates much lower than these values occur in the Wolston sands. Thus, flow rate inhibition of degradation should not be significant. Reaction rates in Rees \& King's experiments did not fit either zero or first order reaction rate models due to inhibitory effects as concentration increased. This suggests that, adjacent to the lagoons, it is possible that different rate equations to those applicable to the remainder of the aquifer would be needed to model this region of the pollution plume in detail. However, since this zone is small, the errors introduced by assuming a first order reaction rate model with constant coefficients over the whole of the modelled region have been assumed to be insignificant.

Using the data provided in Rees \& King (1981) as a basis for examining the impact of biodegradation, a set of simulations was carried out. Degradation of only the adsorbed phenol was assumed in these simulations. Values for $\gamma_{1}^{s}$ ranging between $1 \times 10^{-6}$ and $1 \times 10^{-5} \mathrm{~s}^{-1}$ were input to the model and a distribution coefficient, $K_{D}$ of $1 \times 10^{-8} 1 / \mathrm{mg}$ was adopted for all simulations. From these simulations, a value for $\gamma_{1}^{s}$ of $1 \times 10^{-6} \mathrm{~s}^{-1}$ produces a plume size consistent with the observations; however, uncertainties in the rate of injection of leachate into the aquifer suggest that values up to $4 \times 10^{-6} \mathrm{~s}^{-1}$ might be possible. Nevertheless, the concept that, in addition to advection and dispersion, both degradation and adsorption are primary processes affecting the migration of phenol in the Wolston Sands has been shown to be consistent with observations. Further discussions of the groundwater chemistry at the Villa farm site can be found in Higgo et al. (1996) and Williams (1999).

\section{Discussion}

In the analysis of conceptual model uncertainty, it was found that recalibration of alternative models using typical measures of goodness of fit to the head and hydraulic gradient data failed to discriminate between a wide range of models exhibiting very different flow directions in the aquifer. This insensitivity is partly attributable to the low gradients in the vicinity of the main body of the plume for this particular aquifer. It is also partly attributable to the pattern of observations, which have more to do with the delineation of the plume structure than the flow system. The trade-off in knowledge gained during a site investigation between focusing data collection more on the analysis of flow or more on chemical behaviour is clearly a complex design issue and one that deserves greater study. As illustrated by the present research, emphasis on one area to the exclusion of the other can lead to surprising results in terms of the knowledge acquired and the residual uncertainty in any subsequent data analysis.

In the flow modelling, no account was taken of the chemical data in the formulation of the alternative conceptual models. Although this has not been tested in detail, it seems likely that, had this been undertaken, several alternative flow systems derived from the process of recalibration would be eliminated by forward modelling the chloride plume and comparison of the results with the chemical field data. However, it is also apparent from this study that, even with acceptable fits to the contaminant observations, strong differences can exist between the plume shape obtained from modelling and the plume shape derived by contouring the point observation data (Williams et al. 1984). Thus, considerable care is required to avoid over-constraining the conceptual model uncertainty if joint calibration against flow and transport data is adopted that embeds a priori concepts of plume shape. There is considerable scope for further research in this area and into the worth of incorporating different data types (such as head and concentration data) in reducing conceptual model uncertainty (e.g. Anderman et al. 1996; Medina \& Carrera 1996).

Formal estimates of the uncertainty associated with the choice of conceptual model have not been produced as part of this research, due to the chosen method of conceptual model identification. One useful extension to the current work would be to establish an automated methodology for exploring the space of conceptual model uncertainty to complement current stochastic methods for exploring parameter uncertainty.

Although the current modelling has raised particular issues about the reliability of models for prediction of plume evolution and provided some pointers to areas of development that should be addressed as part of a long-term research initiative, it has provided two useful results. First, the study has provided evidence that the bounds on chemical and biochemical processes quantified in the laboratory can provide an appropriate starting point for identifying likely models and parameter ranges applicable to migration at much larger spatial scales. Second, it has illustrated the significance of the interaction between the leachate source and the aquifer in any predictive assessment of long-term pollution of the aquifer.

\section{Summary and Conclusions}

Through the development of a two-dimensional areal model describing the migration of the leachate from the 
lagoons through the Wolston Sands aquifer, it has been possible to assess quantitatively the major controls governing the development of the plume based on the collected hydrochemical data. Simple models for adsorption and degradation appear from this study to be effective in describing the major features of the pollution plume in the Wolston Sands. Moreover, it appears that values for the parameters of these models obtained from small-scale laboratory investigations can be transferred to large-scale models directly under appropriate conditions. The relative homogeneity of the Wolston Sands formation at Villa Farm, which can be regarded as a single porosity medium with well-defined upper and lower boundaries, may explain why it satisfies these conditions. The extent to which this similarity of chemical behaviour at different scales is valid for more heterogeneous geological environments is an interesting research problem.

The use of Kriging to define the geometry of the aquifer from the borehole data was successful. The additional estimates of the potential magnitudes of the errors in the surfaces provide valuable information on the uncertainty in this component of the overall model. Whilst more objective procedures are needed to fully define the impact of this uncertainty on the final model results, the use of successive manual recalibration was able to provide an indication of the scale of the problem.

Finally, it appears from this study that better methods than those adopted here for identifying the physical processes governing the behaviour of contaminants in groundwater must be sought if the uncertainties associated with the modelling of groundwater pollution are to be reduced. This remains as a challenging problem facing groundwater contaminant migration research.

Acknowledgements. The authors are grateful for the support of the Natural Environment Research Council who funded the work carried out in the Water Resource Systems Research Laboratory at the University of Newcastle upon Tyne by Rae Mackay and Trevor Cooper and completed by Michael Riley. This paper is published with the permission of the Director of the British Geological Survey (Natural Environment Research Council).

\section{References}

Anderman, E. R., Hill, M. C. \& Poeter, E. P. 1996. Two-dimensional advective transport in ground-water flow parameter estimation. Groundwater, 34, 1001-1009.

Anderson, M. P. 1979. Using models to simulate the movement of contaminants through groundwater flow systems. Critical Reviews in Environmental Controls, 9, 97-156.

Boethling, R. S. \& AleXANDER, M. 1979. Effect of concentration of organic chemicals on their biodegradation by natural microbial committies. Applied and Environmental Microbiology, 37, 1211-1216.

Delhomme, J. P. 1979. Spatial variability and uncertainty in groundwater flow parameters: a geostatistical approach. Water Resource Research, 15, 269-280.
Gelhar, L. W., Welty, C. \& Rehfeldt, K. R. 1992. A critical review of data on field-scale dispersion in aquifers. Water Resource Research, 28, 1955-1975.

Higgo, J. J. W., Nielsen, P. H., Bannon, M. P., Harrison, I. \& Christensen, T. H. 1996. Effect of geochemical conditions of fate of organic compounds in groundwater. Environmental Geology, 27, 335-346.

Kitanidis, P. K. 1997. Introduction to GeostatisticsApplications in Hydrogeology. Cambridge University Press.

Klotz, D., Seiler, K. P., Moser, H. \& Neumaier, F. 1980. Dispersivity and velocity relationship from laboratory and field experiments. Journal of Hydrology, 45, 169-184.

Mackay, R., Porter, J. D., Williams, G. M., Ross, C. A. M. $\&$ Noy, D. 1986. Modelling mass transport in the unsaturated zone - a case study. Water Quality Modelling in the Inland Natural Environment. BHRA, Cranfield, U.K., 259-275.

Mackay, R., Burgess, W. G., Cooper, T. A. \& Porter, J. D. 1988. Stochastic modelling of solute migration at a shallow waste repository. Proc. of the International Symposium on the Hydrogeology and Safety of Radioactive and Industrial Hazardous Waste Disposal. Int. Assoc. of Hydrogeologists, Orleans, France, 477-492.

MarsiLy, G. DE. 1986. Quantitative Hydrogeology - Groundwater Hydrology for Engineers. Academic Press, London.

Medina, A. \& Carrera, J. 1996. Coupled estimation of flow and solute transport parameters. Water Resource Research, 32, 3063-3076.

Phillips, F. T. 1964. The aqueous transport of water-soluble rematicides through soils, 1: the sorption of phenol and ethylene dibromide solutions and the chromatographic leaching of phenol in soils. Journal of Science of Food and Agriculture, 15, 444-450.

ReEs, J. F. \& KING, J. W. 1980. The dynamics of aerobic phenol biodegradation in lower greensand. Journal of Chemical Technology and Biotechnology, 30, 396-404.

ReEs, J. F. \& King, J. W. 1981. The dynamics of anaerobic phenol biodegradation in lower greensand. Journal of Chemical Technology and Biotechnology, 31, 306-310.

Shapiro, A. M. 1984. Finite element simulation of groundwater flow and contaminant migration. First Short Course on Groundwater Flow and Pollution. Department of Civil Engineering, University of Newcastle upon Tyne, UK.

Voss, C. I. 1984. A finite element simulation model for saturated-unsaturated, fluid- density-dependent groundwater flow with energy transport or chemically-reactive single-species solute transport. Water Resources Investigation Report, 84-4369. United States Geological Survey, Reston, Virginia, USA.

WiLliams, G. M. 1999. Natural attenuation of aromatic compounds and heavy metals in a lacustrine sand aquifer at Villa Farm, UK. In: Fass, R., FlashneR, Y. \& REuvenY, S. (eds) Novel Approaches for Bioremediation of Organic Pollution. Kluwer Academic/Plenum Publishers, New York, 285-295.

Williams, G. M., Ross, C. A. M., Stuart, A., Hitchman, S. P. \& Alexander, L. S. 1984. Controls on contaminant migration at the Villa Farm Lagoons. Quarterly Journal of Engineering Geology, 17, 39-55.

Williams, G. M., Smith, B. \& Ross, C. A. M. 1992. The migration and degradation of waste organic-compounds in groundwater. Organic Geochemistry, 19, 531-543. 